Eurasian Journal of Educational Research 82 (2019) 45-62

Eurasian Journal of Educational Research
www.ejer.com.tr

\title{
Evaluation Model for Evaluating Vocational Skills Programs on Local Content Curriculum in Indonesia: Impact of Educational System in Indonesia
}

Samsul HADI ${ }^{1}$, Dedek ANDRIAN ${ }^{2}$, Badrun KARTOWAGIRAN ${ }^{3}$

\section{ARTICLE INFO}

Article History:

Received: 24 Feb. 2019

Received in revised form: 25 Jun.2019

Accepted: 13 Jul.2019

DOI: $10.14689 /$ ejer.2019.82.3

\section{Keywords}

evaluation model, vocational skills

programs, local content curriculum

\section{A B S T R A C T}

Purpose: The impact of decentralization on education systems requires the local government to develop local content curriculum to preserve regional characteristics and local uniqueness through education. Practice in the field revealed problems in terms of implementation so that the development of an evaluation model in accordance with the characteristics of the region is necessary. The purpose of this study was to produce an evaluation model for evaluating vocational skills programs on the local content curriculum.

Method: This was a developmental study consisting of three phases: 1) The initial investigative phase was conducted by interviewing vice-principals and vocational skills programs teachers;2) The design phase was carried out by making an instrument, evaluation guide, evaluation procedure and the effectiveness of the model assessment sheet; 3) The trial phases were carried out by performing readability test, small-scale trial, and large-scale trial. Results: The results of the readability test indicated that evaluation instrument, evaluation guide, and evaluation procedure were feasible to use, and according to experts the model was very effective to evaluate vocational skills programs on the local content curriculum. The result of the small-scale trial showed that the 24 items developed were valid and reliable. Large-scale trial results indicated that the instrument had acceptable validity and reliability of the construct.

Implications for Research and Practice: Evaluation models that have been developed, validated by experts, validated by practitioners and trials on the small and large-scale can contribute to improving vocational skills programs on the local content curriculum developed by local governments throughout Indonesia and even other countries.

\footnotetext{
${ }^{1}$ Corresponding Author, Postgraduate Program, Yogyakarta State University, Email samsul_hd@uny.ac.id ORCID: https://orcid.org/0000-0003-3437-2542

${ }^{2}$ Mathematics Education , Riau Islamic University, Email: dedekandrian@edu.uir.ac.id .ORCID:https://orcid.org/ 0000-0001-5192-2222

3 3Postgraduate program, Yogyakarta State University, Email: : kartowagiran@uny.ac.id ORCID: https:/ / orcid.org/0000-0002-8536-5417
} 


\section{Introduction}

Efforts to conserve natural resources or local uniqueness have been thought by the central government. The central government has established an organized system in a school curriculum that is called the local content curriculum. This is stipulated in the regulation of the Minister of Education and Culture No. 22 of 2006 in content standards stating that local content and self-development activities are an integral part of the curriculum structure at elementary and secondary education levels. This is based on the facts that the Unitary State of Republic of Indonesia consists of various regions of diverse geographical conditions, natural resources, and communities with different historical and cultural backgrounds (Depdiknas, 2006).

The central government has made a policy to accommodate the needs of local governments in efforts to develop natural resources or uniqueness of the region. The policy is run through education contained in the curriculum that is packaged in learning activities. Government policies facilitate regions to develop natural resources or potential areas into a product that can improve the economy of the society. Local content becomes an effective means to preserve and develop regional potentials. Local content curriculum to bridge learners to adopt the potential of the region so that through the bridge the learner can develop and preserve the environment into something useful. The introduction of local culture through teaching and classroom activities can essentially help students to recognize their cultural identity (Prastiwi, 2013). The local content curriculum makes learners able to generate useful creativity in improving the economy if the learners do not continue to university education.

The importance of the role of local content implemented in schools is undeniable. Local content is very important in maintaining the local wisdom of a region (Saputra, 2013). Local content can help the government in realizing the local vision to enrich students with the local cultural knowledge and improve students' ability to socialize it to other areas (Prastiwi, 2013). Therefore, the activity of local content learning that runs continuously in a learning system is expected to contribute overall to make the formation of students' character who love local culture.

Many studies, which were inspired by Gardner's AMTB, were conducted in maintaining the regional uniqueness and preserving the local culture, local government from Riau Province developed a local content curriculum by implementing vocational skills programs. Vocational skills programs are expected to be a weapon and an effective way to preserve the uniqueness and culture through educational programs. Vocational programs are the main programs to introduce regional and cultural characteristics to learners. Learners as a young generation are expected to maintain uniqueness and develop a regional culture with the existence of a vocational skills program. Vocational skills programs are expected to contribute greatly to preserving regional uniqueness and culture. Vocational skills program on the local content curriculum is expected to be a program that can develop the uniqueness of the region and culture so that it can improve the economy of students, schools, and regions. 
The curriculum is a sum of the learning activities and experiences that a student has under the auspices or direction of the school (Fink, C.R .\& Crunkilton, 1999; Howell, K.W. \& Nolet, 2000). The curriculum is an educational process undertaken from determining the process, methods, teaching strategies, means, and infrastructure, where the educational function is taught (Sorenson, Goldsmith, Mendez\& Maxwell, 1979). This curriculum refers to planned learning experiences that the educational institution intends to provide for its learners (Uys \& Gwele, 2005). The curriculum is a learning experience planned by educational institutions that are provided for learners (Syomwene, Kitainge \& Mwaka, 2013). The curriculum is an important part of the education system because the curriculum is a framework that expresses goals, expectations, and means (Suryadi, Ekayanti, \& Euis, 2017). The curriculum is total means through students by school guidance.

Curriculum evaluation is an integral part of curriculum development activities. The developed curriculum needs to be evaluated to see the achievement of the objectives of the curriculum. However, curriculum evaluation is not only used to obtain information about achievement but also as a measure of the value or effectiveness of any particular activity in education. The curriculum evaluation refers to the collection of information in which judgment might be made about the worth and the effectiveness of a particular program (Hussain, Dogar, Azeem \& Shakoor, 2011). Curriculum evaluation refers to the process of studying the merit or worth of some aspects, or the whole curriculum (Bharvad, 2010). Curriculum evaluation has a very important role in gaining information about the achievement of the developed curriculum. Curriculum evaluation is a systematic way of examining all components of a curriculum whose results are evaluative inferences (Uys \& Gwele, 2005). Curriculum evaluation is an important aspect that can answer fundamental questions about the achievement of the purpose of developing a curriculum (Akker \& Verloop, 1994). From the description of curriculum evaluation, it can be concluded that evaluators or stakeholders can check the success of the curriculum through basic questions with reference to the objectives of the developed curriculum. Curriculum evaluation has an important role in detecting the success of learning because the problems of learning results that are not achieved are often addressed in the curriculum. Curriculum evaluation has an important role in identifying issues occurring in the curriculum and ensuring the quality of schools and influencing the success of the curriculum (Yeung, 2010). Curriculum evaluation is a phase of selecting information, obtaining, analyzing, transferring, using and making decisions to improve the quality of the curriculum (Hakan \& Seval, 2011).

The National Research Council (2004) states that three framework components must be determined to evaluate the curriculum; (1) program materials and principles in curriculum design, (2) quality of curriculum implementation, (3) curriculum impact on student achievement. These three components can show how effectively the curriculum has been developed. The evaluation of the curriculum is to analyze the process and impact of activities running in the school curriculum (Figueiredo, Leite \& Fernandes, 2016). Through curriculum evaluation, the understanding, practice of 
teaching, learning and assessment can be improved (Leathwood\& Phillips, 2000). This shows that the curriculum is the basis of the success of teaching and learning in class.

An understanding of the problem in learning can be developed by investigating or evaluating the curriculum being applied (Haghparast, Sedghizadeh, Shuler, Ferati \& Christersson, 2007). Significant attention to improving the curriculum is something that must be given at the level of state, nation and region. Concrete steps should be taken by evaluating the curriculum. Interest in evaluating the curriculum should grow as a major effort to improve the curriculum. curriculum evaluation provides illustrations of problems experienced in learning activities, then schools can create a formula or problem-based model to solve the problem (Harlacher, Sakelaris \& Kattelman, 2014). Schools can explicitly explore approaches that can be used to improve the applied curriculum (Adin-Surkis, 2016). Curriculum evaluation is an important point to show how far students have achieved the competence of the learning process (Merritt, Blake, McIntyre \& Packer, 2012). Based on this it can be concluded that the good or bad standard of a curriculum can be seen by evaluation. The gaps in curriculum implementation can be seen clearly by conducting curriculum evaluation.

Vocational skills programs are the impacts of local content curriculum implementation developed by the local government. Vocational skills programs become an effective means of improving the economy. Vocational skills programs applied through the education system can improve the economy of society (Akshay et al., 2013). Vocational skills programs that are still in continuous training can improve the economic productivity of a region (Powell, Bernhard \& Graf, 2012). Vocational skills program in the application can improve communication skill, interpersonal skills, group work, and problem-solving skills of the students (Hassall, Joyce, Montaño, \& Anes, 2005; Montano, Donoso, Hassall \& Joyce, 2001). Vocational skills programs taught sustainably throughout education can develop the ability to plan, encourage sustainable work practices and develop strategies in the workforce (Brown, 2013)

Based on the definition of experts it can be concluded that the evaluation of vocational skills programs on the local curriculum is an important thing to do. The success of the curriculum can be observed through curriculum evaluation. The curriculum evaluation will examine in detail the factors that may affect the success of students' vocational skills in the local curriculum. Evaluation of a vocational skills program in the local content curriculum can provide a comprehensive picture of government-developed curriculum achievement. Vocational skills programs in the local content curriculum should be thoroughly evaluated. This is because the vocational skills programs in the local content curriculum are developed based on the objectives, background, policy and needs analysis equipped with infrastructure and supporting elements to achieve the objectives. The components underlying the vocational skills in the local curriculum need to be evaluated so that known weaknesses could be corrected. 


\begin{abstract}
Method
Research Design

Evaluation model for evaluating the implementation of vocational skills programs in the local content curriculum in Indonesia: Impact The education system in Indonesia uses a research and development model from Borg and Gall (1983) consisting of 10 steps simplified into three steps: (1) initial investigation phase, (2) design phase, and (3) trials phase. The initial investigation was conducted with a qualitative research approach that is phenomenology. Data were collected (FGD) with 16 Participants consisting of 8 vice-principals and 8 vocational skills programs teachers. The purpose of FGD was to find problems about the implementation of vocational skills programs on the local content curriculum and to find the constructs used to develop the instrument. From of the FGD four constructs have obtained that need to be evaluated in terms of the implementation of vocational skills programs on the local content curriculum namely, learning facilities, teacher preparation, learning implementation, and assessment. The design phase was conducted by developing a questionnaire and an interview guide. The small-scale trial aims to see the validity of the contents empirically to the items of the questionnaire that has been developed. The large-scale trial aims to see the validity and reliability of the construct of the questionnaire that has been developed
\end{abstract}

\title{
Research Sample
}

The sample used in this research is the vice principal, vocational skill program teachers, and senior high school students applying a vocational skills program on the local content curriculum. The initial investigative phase involved 8 vice-principals and 8 vocational skills programs, teachers. The small-scale trial phase involved 180 senior high school students in Riau Province. The large-scale trial phase involving 300 senior high school students. The sampling technique used is purposive sampling because it can select the samples correctly according to the criteria and the number of samples to be used for the research (Eğmir, Erdem \& Koçyiğit, 2017).

\section{Research Instruments and Procedures}

The instrument used in this study is a questionnaire and an interview guide. The questionnaire and interview guide that has been developed is then validated by experts and practitioners. The questionnaire developed amounted to 24 items consisting of 6 items of Learning facilities, 5 items of teacher preparation, 7 items of curriculum implementation, 6 items of assessment. The interview guide developed amounted to 12 questions. The development of the instrument was conducted through the results of the initial investigation.

\section{Data Analysis}

There were three phases of data analysis performed in this research. Data analysis of the initial investigation phase, data analysis of small-scale trial data and data analysis of the large-scale trial. Data analysis at the initial investigative phase used the method proposed by Miles \& Huberman (1994): data reduction, data display, and 
conclusion. Data analysis at the small-scale trial phase was held using exploratory factor analysis to see the validity of content empirically. The data analysis of the largescale trial phase also used confirmatory factor analysis to see the validity of the constructs.

\section{Results}

\section{Design Phase}

The design phase was conducted by developing a questionnaire and an interview guide. Questionnaire and interview guide were assessed by experts and practitioners. The expert and practitioners' assessment can be seen at the readability test as follows:

\section{Readability Test}

The readability test aimed to obtain an assessment or validation from the evaluation experts, measurement experts, vice principals, vocational skill programs teachers about the quality of the instrument, evaluation guide, evaluation procedure and effectiveness of the developed model. The readability test was done by 2 evaluation experts, 2 measurement experts, 4 vice principals, and 4 vocational skills programs teachers. The results of the readability test were analyzed using descriptive analysis and comparing with the criteria of product validity proposed by Sultan, et al. (2017). The product validation criteria table can be seen in Table 1.

\section{Table 1}

Criteria for Product Validity

\begin{tabular}{ll}
\hline Average Score & Category \\
\hline $3.26-4.00$ & Very feasible \\
\hline $2.51-3.25$ & Feasible \\
\hline $1.76-2.50$ & Feasible enough \\
\hline $1.00-1.75$ & Not feasible \\
\hline
\end{tabular}

\section{Readability Test of the Questionnaire}

The Readability test of the Questionnaire was performed to see how far the instruments are feasible to be used to evaluate vocational skills programs on the local content curriculum. There are seven aspects that are assessed in the instrument of questionnaire that is, 1) clarity of instructions to use the Instruments, 2) communicative language use, 3) the choice of words, 4) the structure of sentences, 5) multi-interpretation, 6) evaluation of local content curriculum at high schools in Riau Province, and 7) usability of the instruments. The result of an expert and practitioner assessment can be seen in Table 2 . 
Table 2

Readability Test of Questionnaire

\begin{tabular}{cccccc}
\hline Aspects assessed & Min & Max & Mean & $\begin{array}{c}\text { Standard } \\
\text { deviation }\end{array}$ & Category \\
\hline Aspect 1 & 3.00 & 4.00 & 3.750 & 0.452 & Very feasible \\
Aspect 2 & 3.00 & 4.00 & 3.667 & 0.492 & Very feasible \\
Aspect 3 & 2.00 & 4.00 & 3.333 & 0.651 & Very feasible \\
Aspect 4 & 3.00 & 4.00 & 3.417 & 0.515 & Very feasible \\
Aspect 5 & 3.00 & 4.00 & 3.500 & 0.522 & Very feasible \\
Aspect 6 & 3.00 & 4.00 & 3.667 & 0.492 & Very feasible \\
Aspect 7 & 3.00 & 4.00 & 3.750 & 0.452 & Very feasible \\
\hline
\end{tabular}

Based on Table 2 it can be concluded that according to experts and practitioners the developed instruments can be used to evaluate vocational skills programs on the local content curriculum of the senior high school in Riau Province because the lowest average score was 3.33 with a very feasible category.

\section{Readability Test of the Interview Guidance}

The readability test on interview guides was done to see how far the instruments of interview guidance can be used by education offices, principals, and teachers. The Readability test was also assessed by experts and practitioners. There are seven aspects that are assessed in the instrument of the interview guidance that are, 1) clarity of instructions to use the instruments, 2) communicative language, 3) the choice of words, 4) the structure of sentences, 5) multi-interpretation, 6) evaluation of the local content curriculum at high schools in Riau Province, and 7) usability of the instruments. The results of the expert and practitioner assessment can be seen in Table 3 .

Table 3

Readability Test of Interview Guidance

\begin{tabular}{cccccc}
\hline Aspects assessed & Min & Max & Mean & $\begin{array}{c}\text { Standard } \\
\text { deviation }\end{array}$ & Category \\
\hline Aspect 1 & 3.00 & 4.00 & 3.58 & 0.51 & Very feasible \\
Aspect 2 & 2.00 & 4.00 & 3.25 & 0.75 & Feasible \\
Aspect 3 & 3.00 & 4.00 & 3.58 & 0.51 & Very feasible \\
Aspect 4 & 2.00 & 4.00 & 3.33 & 0.65 & Very feasible \\
Aspect 5 & 2.00 & 4.00 & 3.50 & 0.67 & Very feasible \\
Aspect 6 & 2.00 & 4.00 & 3.50 & 0.67 & Very feasible \\
Aspect 7 & 2.00 & 4.00 & 2.92 & 0.79 & Feasible \\
\hline
\end{tabular}


Based on Table 3 it can be concluded that according to experts and practitioners the developed instruments in the form of interview guidance can be used to evaluate vocational skills programs on the local content curriculum of the senior high schools in Riau Province, because the lowest average score was 2.92 with feasible category.

\section{Readability Test of the Evaluation Guide}

Assessment of evaluation guidance helped to see how far the developed evaluation guide can be comprehended and used to evaluate vocational skills programs on the local content curriculum. There are several important points to consider in terms of evaluation guide that are, 1) evaluation model of vocational skill program can be used to diagnose weakness or deficiency in vocational skills program, 2) user of this model is principal, vice-principal, and teacher, 3) model evaluation will evaluate important components in vocational program, 4) this model is used after school exams, 5) Instrument in this evaluation model uses likert scale and interview guide, 6) Students are required to fill in their names and class in available column, 7) student are asked to read the instructions in the instrument carefully, and 8) the time provided to answer the statement is one hour. The assessment was done by experts and practitioners. There are nine aspects assessed on the evaluation guide namely; 1) the instructions in the evaluation guide, 2) the steps in the evaluation, 3) how to use the evaluation model, 4) clarity of time to carry out an evaluation, 5) communicative language use, 6) the structure of sentences, 7) the choice of words, 8) multi-interpretation, and 9) ease of the evaluation guide. The results of the assessment can be seen in Table 4 .

\section{Table 4}

Results of Assessment of Expert EPractitioners

\begin{tabular}{cccccc}
\hline Aspects assessed & Min & Max & Mean & $\begin{array}{c}\text { Standard } \\
\text { deviation }\end{array}$ & Category \\
\hline Aspect 1 & 2.00 & 4.00 & 3.333 & 0.778 & $\begin{array}{c}\text { Very } \\
\text { feasible }\end{array}$ \\
Aspect 2 & 2.00 & 4.00 & 2.833 & 0.835 & Feasible \\
Aspect 3 & 2.00 & 4.00 & 3.083 & 0.793 & Feasible \\
Aspect 4 & 2.00 & 4.00 & 2.917 & 0.669 & Feasible \\
Aspect 5 & 2.00 & 4.00 & 3.000 & 0.603 & Feasible \\
Aspect 6 & 2.00 & 4.00 & 3.083 & 0.900 & Feasible \\
Aspect 7 & 2.00 & 4.00 & 3.000 & 0.953 & Feasible \\
Aspect 8 & 2.00 & 4.00 & 3.250 & 0.754 & Feasible \\
Aspect 9 & 2.00 & 4.00 & 3.250 & 0.754 & Feasible \\
\hline
\end{tabular}

Based on the assessment of experts and practitioners it can be concluded that the evaluation guide is feasible to be used to evaluate vocational skill programs on the local content curriculum at high schools in Riau Province because all the aspects in the guide were in feasible and very feasible category. 


\section{The Readability Test of the Evaluation Procedure}

Assessment of the evaluation procedure revealed how far the developed procedure can be carried out practically without any difficulties. There are five procedures that must be performed by user evaluation that are, 1) Evaluation is done after 1st semester, 2) Vocational skills program teachers provide tests to see the competence of the students with the instrument that has been designed by the teacher 3) the score of the test results are calculated and compared with the predetermined success criteria, 4) the teacher reports the results of the vocational skills program test subjects to the students, 5) the teacher collects students outside the lesson hours and provides the evaluation instrument of the vocational program to evaluate the overall vocational skills program which has been running for one semester. Assessment of evaluation procedures is done by experts and practitioners. There are seven aspects assessed on evaluation procedure, namely; 1) clarity of evaluation procedures, 2) Effective sentence use, 3) correct use of spelling and punctuation, 4) practicality of the evaluation procedure (easy to follow), 5) Efficiency in terms of time, 6) efficiency in terms of cost, and 7) efficiency in terms of energy. The results of the assessment of experts and practitioners can be seen in Table 5 .

\section{Table 5}

The Results of the Assessment of Experts and Practitioners

\begin{tabular}{cccccc}
\hline Aspects assessed & Min & Max & Mean & $\begin{array}{c}\text { Standard } \\
\text { deviation }\end{array}$ & Category \\
\hline Aspect 1 & 2.00 & 4.00 & 3.417 & 0.669 & $\begin{array}{c}\text { Very } \\
\text { feasible } \\
\text { Very } \\
\text { Aspect 2 }\end{array}$ \\
Aspect 3 & 2.00 & 4.00 & 3.500 & 0.798 & $\begin{array}{c}\text { feasible } \\
\text { Aspect 4 }\end{array}$ \\
Aspect 5 & 2.00 & 4.00 & 2.667 & 0.778 & Feasible \\
Aspect 6 & 2.00 & 4.00 & 3.000 & 0.953 & Feasible \\
Aspect 7 & 2.00 & 4.00 & 2.750 & 0.866 & Feasible \\
& 2.00 & 4.00 & 2.917 & 0.669 & Feasible \\
& 2.00 & 4.00 & 3.083 & 0.900 & Feasible \\
\hline
\end{tabular}

Based on the assessment of experts and practitioners it can be concluded that the developed evaluation procedure was feasible to be used to evaluate vocational skills program on the local content curriculum because all aspects were considered to be in the feasible and very feasible category.

\section{Assessment of the Effectiveness of the Developed Model}

Testing the effectiveness of the model helped to see whether the developed model could be implemented easily and effectively to evaluate vocational skill programs on the local content curriculum. The test of the effectiveness of the model was held by experts and practitioners. There are six aspects assessed on the effectiveness of the 
developed model, namely; 1) comprehensiveness of the developed model, 2) the accuracy of the model to evaluate local content curriculum, 3) The accuracy of the instrument type, 4) guidance in the implementation of the locals, 5) Ease of use of the instrument, and 6) the evaluation report. The effectiveness test results can be seen in Table 6 .

Table 6

The Results of Effectiveness Test

\begin{tabular}{cccccc}
\hline Aspects assessed & Min & Max & Mean & $\begin{array}{c}\text { Standard } \\
\text { deviation }\end{array}$ & Category \\
\hline Aspect 1 & 2.00 & 4.00 & 3.417 & 0.669 & Very Good \\
Aspect 2 & 2.00 & 4.00 & 3.083 & 0.669 & Good \\
Aspect 3 & 2.00 & 4.00 & 2.917 & 0.793 & Good \\
Aspect 4 & 2.00 & 4.00 & 2.667 & 0.778 & Good \\
Aspect 5 & 2.00 & 4.00 & 2.583 & 0.669 & Good \\
Aspect 6 & 2.00 & 4.00 & 3.000 & 0.739 & Good \\
\hline
\end{tabular}

Based on the results of effectiveness test assessed by experts and practitioners, it can be concluded that evaluation model developed was effective and easy to use to evaluate vocational skills programs on the local content curriculum. All aspects were considered by experts and practitioners in the good and very good category.

\section{Trial Phases}

\section{Small-Scale Trial}

The small-scale trial was analyzed using exploratory factor analysis with varimax rotation method. The analysis results obtained by Kaiser-Meyer-Olkin Measure of Sampling Adequacy (KMO) was $0.907(\mathrm{KMO}>0.5)$ and Bartlett's Test of Sphericity was $0.00(\alpha<0.05)$. The value indicates that the sample used was feasible to analyze using factor analysis. Furthermore, we can see that the loading factor was obtained by varimax rotation method. The result of exploratory factor analysis with varimax rotation method obtained four factors. The result of the analysis can be seen in Table 7. 
Samsul HADI - Dedek ANDRIAN - Badrun KARTOWAGIRAN

Table 7

The Results of Exploratory Factor Analysis With Varimax Rotation Method

\begin{tabular}{|c|c|c|c|c|}
\hline \multirow{2}{*}{ Item } & \multicolumn{4}{|c|}{ Component } \\
\hline & Factor 1 & Factor 2 & Factor 3 & Factor 4 \\
\hline Learning Facilities 1 & & & & 0.850 \\
\hline Learning Facilities 2 & & & & 0.786 \\
\hline Learning Facilities 3 & & & & 0.683 \\
\hline Learning Facilities 4 & & & & 0.775 \\
\hline Learning Facilities 5 & & & & 0.622 \\
\hline Learning Facilities 6 & & & & 0.773 \\
\hline Teacher Preparation 1 & & & 0.918 & \\
\hline Teacher Preparation 2 & & & 0.870 & \\
\hline Teacher Preparation 3 & & & 0.844 & \\
\hline Teacher Preparation 4 & & & 0.837 & \\
\hline Teacher Preparation 5 & & & 0.908 & \\
\hline Curriculum Implementation 1 & 0.880 & & & \\
\hline Curriculum Implementation 2 & 0.872 & & & \\
\hline Curriculum implementation 3 & 0.866 & & & \\
\hline curriculum Implementation 4 & 0.782 & & & \\
\hline curriculum Implementation 5 & 0.849 & & & \\
\hline curriculum Implementation 6 & 0.790 & & & \\
\hline curriculum Implementation 7 & 0.860 & & & \\
\hline Assessment 1 & & 0.911 & & \\
\hline Assessment 2 & & 0.844 & & \\
\hline Assessment 3 & & 0.855 & & \\
\hline Assessment 4 & & 0.739 & & \\
\hline Assessment 5 & & 0.831 & & \\
\hline Assessment 6 & & 0.847 & & \\
\hline Total of Eigen Values & 10.303 & 3.418 & 3.040 & 1.811 \\
\hline Percentage of variance explained & 42.930 & 14.241 & 12.666 & 7.548 \\
\hline KMO & & & & .907 \\
\hline Bartlett's test of sphericity* & & & & 4179.312 \\
\hline $\mathrm{df}$ & & & & 276 \\
\hline $\operatorname{sig}$ & & & & 0.000 \\
\hline
\end{tabular}

a. Rotation converged in 5 iterations. 
Based on Table 6, it can be concluded that 24 items that have been rotated by the varimax rotation formed into 4 factors. The first factor was the implementation of the curriculum, the second factor was the assessment, the third factor was the preparation of teachers, and the fourth factor was learning facilities. The four factors formed had a loading factor value of more than 0.5 , so it can be concluded that the items that have been developed were valid and fit to be used to evaluate vocational skills programs on the local content curriculum. (Hair Jr, William, Babin\& Anderson, 2014).

\section{Reliability of Instrument}

Reliability was tested using Cronbach's Alpha. This result indicated that the instrument was reliable because it has a value of Cronbach's Alfa 0.940. The result can be seen in Table 8 .

\section{Table 8}

Reliability Statistics

\begin{tabular}{cc}
\hline Cronbach's Alpha & N of Items \\
\hline 0.940 & 24 \\
\hline
\end{tabular}

\section{Large-Scale Trial}

The large-scale trial was utilized to find the validity and reliability of constructs obtained by the evaluation component that became the basis to evaluate the vocational skill programs on the local content curriculum. This construct should be empirically tested and analyzed using statistical confirmatory factor analysis. The purpose of this analysis was to determine the validity and reliability of constructs obtained by initial investigations with qualitative research approaches. The results of the analysis can be seen in Table 8.

\section{Table 9}

Validity and Reliability of Construct

\begin{tabular}{ccccc}
\hline Factor & Indicator & $\lambda$ & Error & CR \\
\hline Factor 1 & Curriculum & & & \\
& Implementation & 0.856 & 0.267 & \\
Factor 2 & Assessment & 0.793 & 0.371 & 0.884 \\
Factor 3 & Teacher Preparation & 0.830 & 0.311 & \\
Factor 4 & Learning Facilities & 0.756 & 0.428 & \\
\hline
\end{tabular}

The results of confirmatory factor analysis showed that four factors had a factor load value of more than 0.5 , so it can be concluded that four factors had validity and reliability of the constructs in good categories. The results of confirmatory factor 
analysis showed that the four-factor met the goodness of fit statistics because they had Chi-Square value <2df, P-value $>0.05$, and RMSEA <0.08, GFI $>0.9$ and AGFI $>0.9$. In other words, the model developed in accordance with the data that has been obtained in the field.

\section{Discussion, Conclusion, and Recommendations}

The readability test shows that the developed instruments in the form of questionnaires and interview guides are in a category worthy of use to evaluate vocational skills programs in local content curricula. All the aspects used to assess the instruments are in a decent and highly feasible category. The readability test of the instruments is an important part to consider in developing the model because the instruments will be used by education offices, principals, and teachers who have never used the instruments before to evaluate vocational programs. Education offices, principals, and teachers who have understood the contents of developed instruments can provide explanations to students as subject and object evaluation models when they implement evaluation models. Instruments have validated by experts can give good data or information about the effectiveness of local content curriculum (Andrian, Kartowagiran, \& Hadi, 2018). The evaluation guide is a guide to the education office, principals, and teachers as users of the evaluation model that has been developed. The guide for evaluating vocational skills programs in the local curriculum should be thoroughly understood by the users of the vocational skills program evaluation model. The evaluation guide can provide an ease to the users in implementing the evaluation model directly in the field. High understanding of the evaluation guide on the program evaluation model can avoid errors in the process of data collection.

Evaluation procedures are the steps that the user of the vocational skills program evaluation model should follow. The steps in the evaluation need to be done carefully so that the users of the evaluation model of the vocational skill program are not confused in the implementation of the evaluation model that has been developed. The users must read the procedure in order not to make mistakes in implementing the evaluation model of vocational skill program. Procedures can be a compass for education offices, principals and teachers and evaluation agencies in evaluating vocational programs. Assessment of model effectiveness is an important part of developing an evaluation model of vocational skills programs in the local content curriculum. An effective evaluation model will make it easier for users to evaluate vocational skills programs in terms of fund use, time use and physical capacity utilization, as good evaluation models do not incriminate users to evaluate vocational programs. An effective evaluation model can make it easier for users to get data in the field and process the data into a conclusion that can improve vocational skill program that runs in Riau Province.

Based on the research results, it can be concluded that the evaluation model for evaluating vocational skill programs on local content curriculum that has been developed is supported by a valid and reliable instrument. These results suggest that 
evaluation models can help improve the implementation of vocational skills programs in the local content curriculum. Accurate information obtained from valid and reliable instruments can give you an idea of what needs to be fixed. Ungar \& Santos (2003) state that the instruments having content and construct validity can acquire valuable information. Valid and reliable instruments are important for evaluating educational programs including the curriculum. Loiacono, Watson \& Goodhue (2007) state that instruments that have the power of validity can acquire deep and wide information. Information about the strengths and weaknesses of educational programs can be detected. Validity and reliability are required in instrument development. Valid and reliable instruments can accurately represent the results of research (Burton \& Mazerolle, 2011). Valid and reliable instruments can describe the quality of a measurement (Bayraktar, Tatoglu \& Zaim, 2008). Trials need to be taken seriously, in order to obtain accurate data.

\section{Conclusion}

The evaluation model developed consists of; evaluation instrument, evaluation procedure, evaluation guide, and evaluation effectiveness model sheet. The results of the assessment indicated that the instrument, evaluation guide, and evaluation procedure were feasible to be used to evaluate vocational skills programs on the local content curriculum. According to experts and practitioners, the evaluation model is very effectively used for evaluating vocational skills programs on the local content curriculum. The results of the small-scale trial obtained a value of the loading factor greater than 0.5 or valid, and Cronbach's Alpha value was greater than 0.7 or reliable. The construct instruments that have been developed have validity, reliability, and model fit that can be accepted. All developed factors have a loading factor value greater than 0.5 and a reliability of construct coefficient above 0.7. Value of Chi-Square $<2 \mathrm{df}$, P-Value value greater than 0.5, RSMEA value $<0.08$, GFI value greater than 0.9 . and the AGFI value is greater than 0.9 .

\section{Recommendations}

Evaluation of vocational skills programs on local content curriculum should be carried out continuously or periodically so that weaknesses and deficiencies can be detected immediately. Local governments, principals, and teachers should collaborate in implementing an evaluation model so that the goal of preserving regional uniqueness and local culture through vocational skills learning can be achieved maximally. 


\section{References}

Andrian, D., Kartowagiran, B., \&Hadi, S. (2018). The instrument development to evaluate local curriculum in Indonesia. International Journal of Instruction, 11(4), 921-934. https://doi.org/10.12973/iji.2018.11458a

Adin-Surkis, A. (2016). Teachers evaluate the new curriculum in English: Views regarding evaluation and evaluation tools. Research in Education, (93). https://doi.org/http://dx.doi.org/10.7227/RIE.0009

Akker, J.V.D., \& Verloop, N. (1994). Evaluation approaches and results in curriculum research and development in The Netherlands. Studies in Educational Evaluation, 20(4), 421-436. doi:10.1016/0191-491x(94)00035-f

Akshay, N., Deepu, S., Rahul, E. S., Ranjith, R., Jose, J., Unnikrishnan, R., \& Bhavani, R. R. (2013). Design and evaluation of a haptic simulator for vocational skill Training and Assessment. IECON Proceedings (Industrial Electronics Conference), 6108-6113. https://doi.org/10.1109/IECON.2013.6700139

Bayraktar, E., Tatoglu, E., \& Zaim, S. (2008). An instrument for measuring the critical factors of TQM in Turkish higher education. Total Quality Management $\mathcal{E}$ Business Excellence, 19(6), 551-574. doi:10.1080/14783360802023921

Bharvad, A. J. (2010). Curriculum Evaluation, I(12), 2009-2011.

Borg, W R \& Gall, M. D. (1983). Educational Research Forth Edition. New York: Longman.

Brown, M., Sack, F., \& Piper Rodd, C. (2013). Student voice in "skills for sustainability": A missing component from the demand side of Australian vocational education and training. International Journal of Training Research, 11(3), 213 224. doi:10.5172/ijtr.2013.11.3.213

Burton, L. J., \& Mazerolle, S. M. (2011). Survey Instrument Validity Part I: Principles of Survey Instrument Development and Validation in Athletic Training Education Research. Journal of Athletic Training Education, 6(1), 27-35.

Council, N. R. (2004). On evaluating curricular effectiveness judging the quality. Washington: National Academies Press.

Depdiknas. (2006). Regulation of the Minister of National Education of the Republic of Indonesia Number 22 of 2006. Appendix About Standard Content, 1-48

Eğmir, E., Erdem, C., \&Koçyiğit, M. (2017). Trends in educational research: A content analysis of the studies published in international journal of instruction. International Journal of Instruction, 10(3), 277-294. https://doi.org/10.12973/iji.2017.10318a

Figueiredo, C., Leite, C., \& Fernandes, P. (2016). The curriculum in school external evaluation frameworks in Portugal and England. Research in Comparative and International Education, 11(3), 282-297. https://doi.org/10.1177/1745499916661933 
Fink, C.R., \& Crunkilton, J. (1999). Curriculum development in vocational and technical education. Planning, content, and implementation. Boston: Allyn and Bacon Inc.

Haghparast, N., Sedghizadeh, P. P., Shuler, C. F., Ferati, D., \&Christersson, C. (2007). Evaluation of student and faculty perceptions of the PBL curriculum at two dental schools from a student perspective: a cross-sectional survey. European Journal of Dental Education, 11(1), 14-22. https://doi.org/10.1111/j.16000579.2007.00423.x

Hair Jr, J. F., William, C., Babin, B. J., \& Anderson, R. E. (2014). Multivariate data analysis. Upper Saddle River: Pearson

Hakan, K., \& Seval, F. (2011). CIPP evaluation model scale: development, reliability and validity. Procedia - Social and Behavioral Sciences, 15, 592-599. doi:10.1016/j.sbspro.2011.03.146

Hassall, T., Joyce, J., Arquero Montaño, J. L., \& Donoso Anes, J. A. (2005). Priorities for the development of vocational skills in management accountants: A European perspective. Accounting Forum, 29(4), 379-394. doi:10.1016/j.accfor.2005.03.002

Howell, K.W.,\&Nolet, V. (2000). Curriculum based evaluation: teaching and decision making. Belmont: Wadswortth Thomson Learning.

Hussain, A., Dogar, A. H., Azeem, M., \& Shakoor, A. (2011). Evaluation of Curriculum Development Process. International Journal of Humanities and Social Science, $1(14), 263-271$.

Leathwood, C., \& Phillips, D. (2000). Developing curriculum evaluation research in higher education : Procesa, politics and practicalities. Higher Education, 40(3), 313-330. https://doi.org/10.1023/a:1004183527173

Loiacono, E., Watson, R., \& Goodhue, D. (2007). WebQual: An Instrument for Consumer Evaluation of Web Sites. International Journal of Electronic Commerce, 11(3), 51-87. https:// doi.org/10.2753/JEC1086-4415110302

Merritt, B. K., Blake, A. I., McIntyre, A. H., \& Packer, T. L. (2012). Curriculum evaluation: Linking curriculum objectives to essential competencies. Canadian Journal of Occupational Therapy, 79(3), 175-180. https://doi.org/10.2182/cjot.2012.79.3.7

Miles, M. B., \& Huberman, M. a. (1994). Qualitative data analysis: An expanded sourcebook. Evaluation and Program Planning. https://doi.org/10.1016/0149. 7189(96)88232-2

Montano, J. L. A., Donoso, J. A., Hassall, T., \& Joyce, J. (2001). Vocational skills in the accounting professional profile: the Chartered Institute of Management Accountants (CIMA) employers' opinion. Accounting Education, 10(3), 299313. https://doi.org/10.1080/09639280210122339

Powell, J. J. W., Bernhard, N., \& Graf, L. (2012). The emergent European model in skill formation: Comparing higher education and vocational training in the 
Bologna and Copenhagen processes. Sociology of Education, 85(3), 240-258. https://doi.org/10.1177/0038040711427313

Prastiwi, Y. (2013). Transmitting Local Cultural Knowledge through English as Foreign Language (EFL) Learning as a Means of Fostering "Unity in Diversity." Academic Journal of Interdisciplinary Studies, 2(3), 507-514. https://doi.org/10.5901/ajis.2013.v2n3p507

Saputra, G. A. S. (2013). Enhancing Local Wisdom Through Local Content Of Elementary School in Java, Indonesia. Proceeding Of the Glbal Summit on Education, 2013(March), 11-12.

Sorenson, R., Goldsmith, Ll., Mendez, Z., \& Maxwell, K. (1979). Curriculum development in vocational and technical education. London: SAGE Company.

Sultan, Rofiuddin, A., Nurhadi, \& Priyatni, E. T. (2017). The development of a critical reading learning model to promote university students' critical awareness. New Educational Review, 48(2004), 76-86. https://doi.org/10.15804/tner.2017.48.2.06

Suryadi, B., Ekayanti, F., \& Euis, A. (2017). An integrated curriculum at an islamic university: perceptions of students and lecturers, Eurasian Journal of Educational Research, 67(January), 161-182. https://doi.org/10.14689/ejer.2018.74.2

Syomwene, A., Kitainge, K., \&Mwaka, M. (2013). Psychological influences in the curriculum decision making process. Journal of Education and Practice, 4(8), 173-181. https://doi.org/ISSN 2222-1735.

The National Research Council (2004). On evaluating curricular effectiveness judging the quality of k-12 mathematics evaluations. Washington: The National Academies Press.

Ungar, W. J., \& Santos, M. T. (2003). The pediatric quality appraisal questionnaire: An instrument for evaluation of the pediatric health economics literature. Value in Health, 6(5), 584-594. https://doi.org/10.1046/j.1524-4733.2003.65253.x

Uys, L. R., \& Gwele, N. S. (2005). Curriculum development in nursing: process and innovation, South Africa: Psychology Press.

Van den Akker, J., \& Verloop, N. (1994). Evaluation approaches and results in curriculum research and development in The Netherlands. Studies in Educational Evaluation, 20(4), 421-436. doi:10.1016/0191-491x(94)00035-f

Yeung, S. S. (2010). Using School Evaluation Policy to Effect Curriculum Change? A Reflection on the SSE and ESR Exercise in Hong Kong, Educational Research Journal 25(2), 187-209 
